\title{
A identidade da arqueologia brasileira
}

ULPIANO T. BEZERRA DE MENESES

\section{Comentários ao texto "Existe algo que se possa chamar de 'arqueologia brasileira'?”, de Eduardo Góes Neves}

O texto do Prof. Eduardo Góes Neves, "Existe algo que se possa chamar de 'arqueologia brasileira'?" é lúcido, preciso, criticamente fundamentado, sintonizado com o melhor do pensamento arqueológico contemporâneo e, por isso mesmo, com propostas num rumo muito satisfatório. Obviamente, não se trata de comentá-lo avaliando ou confrontando seus argumentos, pois ele se sustenta perfeitamente sozinho. Suponho que o convite para manifestar-me, feito pelo Prof. Alfredo Bosi, editor-chefe desta revista, se deve, antes, ao fato de que, desde 1964, quando ministrei na Universidade os primeiros cursos teóricos sobre a disciplina, sou uma testemunha que acompanha a trajetória da Arqueologia entre nós, ainda que, nos últimos vinte anos, tenha optado pela História Cultural - mas com foco nos estudos de cultura material e visualidade. Nessa perspectiva, vejo o texto em questão como sinal de um amadurecimento inimaginável na década de 1960, quando nossa Arqueologia pouco ultrapassava os limites dos relatórios de escavações, análises taxonômicas e biografias de sítios.

Seja como for, meu propósito é reverberar as reflexões do autor, aqui e ali inserindo algumas perspectivas de minha preferência, mas sem afetar a consistência de suas posições.

Pertinentemente, Eduardo Neves parte dos compromissos ideológicos e políticos da noção de "arqueologias nacionais", para descartar possíveis critérios identitários como território (de fronteiras aleatórias) ou grau de institucionalização. Também nega validade a categorias eventualmente únicas ou preferenciais de vestígios. Com efeito, a natureza das fontes não basta para determinar a natureza dos problemas de um campo do conhecimento. No entanto, a distorção é corrente, e o mau exemplo vem da História, onde, se a fonte é oral, por exemplo, tem-se a História Oral; se é visual, fala-se de História Visual, e assim por diante. Nessa linha, as fontes escritas deveriam produzir uma História Escrita ou, se houver conjugação de fontes, uma História Multimídia.

Também é considerada insuficiente como marcador a produção de um corpo teórico-metodológico próprio. A exceção apontada pelo autor é a proposição de um corpo teórico e metodológico apropriado ao contexto latino-americano, e sul-americano em particular, pela denominada Arqueologia social latino-americana. 
Em princípio, não vejo como inadequado que se qualifique nacionalmente a contribuição que praticantes de uma disciplina, num determinado país, possam trazer ao corpo teórico-metodológico desse campo do conhecimento. Desde, é claro, que se trate de um fenômeno de marca de "escola", tradições enraizadas, e não de um suposto DNA epistemológico.

Além disso, tenho dúvidas quanto à viabilidade e interesse de uma teoria unificada da Arqueologia, mesmo se desenvolvida como teoria da cultura material. São espaços de convergência, dotados de grande complexidade e fluidez, que perderiam seu dinamismo e fecundidade. Não obstante, vejo como altamente desejável uma interação que articule as migalhas (aproveitando a expressão História em migalhas, de François Dosse (2001)), para as subdivisões em que a disciplina se tem fragmentado, em detrimento do diálogo: Arqueologia pré-histórica, histórica, proto-histórica, clássica, bíblica, medieval, pós-medieval, industrial, simbólica, social etc. Sem dúvida, problemas específicos, contextos específicos, disponibilidade específica de fontes e seu processamento exigem critérios, categorias, ferramentas, métodos e técnicas e estratégias específicas de pesquisa. Não é o caso de ignorar, por fundamentalismo estéril, as necessidades de ordem prática. Contudo, o importante é não sacrificar os interesses epistemológicos por contingências operacionais - ou pior, motivações corporativas e ideológicas - ignorando os caminhos de integração. O problema maior não são os recortes, mas o perigo de eles não serem comunicantes.

Vale concluir afirmando que, embora possa ter sentido falar-se de uma Arqueologia nacional como "boas práticas" que caracterizem um padrão dominante de atuação, uma das precondições é o alargamento do horizonte da pesquisa para além dos espaços domésticos e a interlocução com suas diversas especializações.

A busca de uma marca que sirva de referência, para Eduardo Neves, se inspira na Antropologia Social das terras baixas sul-americanas, nas últimas três décadas, e leva em conta as observações de Anthony Seeger, Roberto da Matta e Viveiros de Castro, sobre a noção de pessoa como ferramenta analítica extremamente fecunda e paradigmática - a exemplo do que ocorreu em cada região etnográfica do mundo, que teve seu "momento na história da teoria antropológica".

Prosseguindo, o autor considera o isolamento geográfico da América do Sul e o quadro da diversidade social, cultural, econômica e política conhecido já no início do contato colonial, e examina aspectos das economias paleoíndias, da produção de alimentos, a indústria cerâmica, a configuração do Estado e conclui pela inadequação de aplicar aqui categorias tipológicas e padrões tidos como universais, mas próprios do Velho Mundo.

Em consequência, supõe que uma contribuição teórica nossa à disciplina passaria por uma "aproximação dos conceitos de história e temporalidade" - em suma, acredito, por aquilo que François Hartog (2003) denominou "regime de historicidade". A proposta, mesmo na sua brevíssima formulação, é instigante, 
mas se é viável etnograficamente, já arqueologicamente apresenta inúmeros percalços. O próprio Eduardo Neves lembra que "a história não está inscrita nos objetos e tampouco são os objetos utilizados como índices para a construção das narrativas históricas”. De fato, do ponto de vista dos grupos estudados, não se pode supor o mesmo tipo de relação que temos com os artefatos. James Clifford (1997) narra uma discussão travada entre antropólogos e anciãos Tlingit sobre uma importante coleção de peças desse grupo (coleção Rasmussen) no Portland Museum of Art, Oregon (Estados Unidos). Os anciãos tinham sido convidados a se manifestar sobre a reorganização da exposição desses objetos, manifestaram respeito por eles, mas pouco interesse, salvo quando algum deles funcionava como gatilho, para narrar "estórias" e entoar cânticos. Em outras palavras, os objetos não tinham valor em si, apenas como mediadores e detonadores de aspectos performáticos da cultura. Ressalve-se, porém, que a desimportância dos artefatos exibidos para os Tlingit é de natureza sobretudo semiótica e não deve excluir forçosamente outras dimensões.

Ora, nossos museus antropológicos e arqueológicos fetichizam os objetos. Um estudo de Miriam Clavir (2002), ao comparar museus ocidentais com os das chamadas "First Nations", revelou que os primeiros asseguram meios físicos e intelectuais para obter que fragmentos materiais do passado não desapareçam: as qualidades culturalmente significativas estão incorporadas à dimensão física do objeto. Já nos museus indígenas, a preservação dos sentidos sociais da coisa física pressupõe levar em conta as relações socioculturais passadas e presentes, para reproduzir a cultura, renovar, continuar as tradições. Preservar a cultura é engajar-se em práticas que garantam seu futuro. $\mathrm{O}$ importante é a produção, $\mathrm{O}$ processo; os museus ocidentais privilegiam os produtos.

Se se deve admitir que a historicidade dos objetos pode ser eventualmente lida na materialidade de sua forma e atributos materiais, já as narrativas necessitam de outros insumos. Além disso, artefatos, embora dotados de potencial linguístico, não são unidades de um código linguístico passível de ter sua chave desvendada. De outra parte, quando se admite que os objetos não são entes passivos, mas dotados de agentividade, produzem efeitos, são instituídos mas também instituem, é preciso supor que sua historicidade não está desvinculada de sua materialidade.

Eduardo Neves completa seu alerta afirmando que "A história, nesses casos, está inscrita na paisagem, nas montanhas, nos afloramentos rochosos e nas cachoeiras, além dos próprios mitos, borrando assim a separação artificial entre mito e história". Talvez fosse prudente desfazer mais que a separação de mito (narração explicativa) e história (aqui é conhecimento controlado? ou a própria dinâmica histórica?), a separação entre artefato e paisagem, pois são ambos integrantes da cultura material, visto como ambos são segmentos da natureza socialmente apropriados. O pressuposto dos estudos de cultura material é a existência de uma dimensão material, física, corporal, sensorial, indispensável à instituição 
e ao desenvolvimento da vida biológica, psíquica e social. É oportuno lembrar que, hoje, cada vez mais o termo inglês "entanglement" (emaranhamento) é usado para caracterizar as relações entre humanos e objetos materiais, seus sistemas, instituições, ambientes, contextos, situações, circuitos (Hodder, 2012).

$\mathrm{Na}$ afirmação das diferenças que tornariam imprópria a utilização de cânones e tipologias de outras partes do mundo para conhecimento das formações arqueológicas sul-americanas, Eduardo Neves refere-se à distinção conceitual entre história e processo formulada pela "New Archaeology" americana dos anos 1970 e 1980. A nova matriz disciplinar exerceu notável papel - apesar de todas as falhas e pretensões descabidas - por ter tratado incisivamente Arqueologia como ciência social. O processo seria "objeto digno de investigação científica", ao passo que a história seria relegada à "lata de lixo do particularismo". Ao mesmo tempo, Eduardo Neves afirma que uma das contribuições mais ricas que a Arqueologia pode proporcionar às Humanidades tem como premissa que aqui a Arqueologia é antes de tudo história. A história, diz ele, ecoando Raymond Aron, é a narrativa da aventura vivida pelos homens.

Acredito que tal perspectiva seja muito fecunda, embora cheia de percalços e deva incorporar o processo social. Percalços, aliás, que o autor não deixa de reconhecer, sobretudo pelas imensas dificuldades metodológicas. É interessante que Aristóteles já tivesse depreciado a História em relação à poesia/mito, pois esses seriam mais amplos, universais (pois se abrem para o que pode acontecer), ao passo que a História dependeria do acontecido, do singular. Ressalte-se que a preocupação com a universalidade do processo e os pressupostos do positivismo lógico levou a "New Archaeology" a uma busca paroxística de "leis gerais do comportamento humano", sem nunca produzir o prometido, mas gerando abundantes "Mickey mouse laws", como ficaram conhecidas.

A polaridade entre o singular e o universal está hoje superada na História (e a micro-história é um bom exemplo dessa convivência). Tanto é assim que Paul Veyne (1977) não se constrangeu em publicar, em 1977, sua aula inaugural no Collège de France sob o título O inventário das diferenças (capaz de se apropriar convenientemente da dimensão do universal), seguido de um subtítulo esclarecedor, "História e Sociologia". De fato, a diferença, tão acentuada por Eduardo Neves, me parece ser o espaço próprio da História - e oportuno para o contexto sul-americano, e lhe cabe na linha de Veyne explicitar a originalidade do desconhecido.

Talvez valha a pena lembrar que a Sociologia não é o único grande parceiro da História. A Antropologia e a Literatura entram no rol de preferências recentes. Num artigo sobre Antropologia, Arqueologia, História e Cultura Material, em coletânea sobre a escrita da cultura material, Kaori O'Connor (2015) remete à Antropologia da História proposta por Marshall Sahlins, definida "como uma história integrada na qual a cultura é história e vice-versa, um projeto para o qual as coisas materiais são centrais". 
Por fim, cumpre reiterar o alerta feito por Eduardo Neves: é preciso olhar menos para fora do continente, em busca de referências teóricas, e, inversamente, mergulhar profundamente nas evidências locais disponíveis. Por paradoxal que pareça, a Arqueologia tem sido nestes últimos tempos acusada de ignorar a materialidade da cultura material e somente agora começa a se preocupar com tal negligência. Voltar ao empírico - principalmente aos artefatos e seu ambiente - não significa fetichizar. Pelo contrário, levando em conta o que se disse antes sobre a agentividade dos artefatos, é necessário deixar de considerá-los exclusivamente como documentos (que eles, naturalmente, não deixarão de ser), para também tratá-los como agentes imersos no jogo social. É preciso, pois, "desdocumentalizar" o documento para entendê-lo, em marcha à ré, na sua biografia social, na sua vida pregressa, antes de situá-lo numa esfera redutoramente cognitiva. Para terminar, a crítica feita ao mau uso da teoria é justíssima, pois ela pode se transformar em cômoda muleta quando dispensada de alimentar perguntas, para só fornecer respostas prontas.

\section{Referências}

CLAVIR, M. Preserving what is valued. Museums, conservation and First Nations. Vancouver: UBC Press, 2002.

CLIFFORD, J. Museums as contact zones. In: Routes: Travel and translation in the late 20-century. Cambridge Mass.: Harvard University Press, 1997 p.188-219.

DOSSE, F. A história em migalhas: Dos Annalles à Nova História. São Paulo: Editora Unesp, 2001.

HARTOG, F. Des régimes d'historicité. Présentisme et expérience du temps. Paris: Seuil, 2003.

HODDER, I. Entangled. An archaeology of the relationship between humans and things. Chichester: Wiley-Blackwell, 2012.

O'CONNOR, K. Anthropology, arcchaeology, history and the material culture of Lycra. In: GERRITSEN, A.; RIELLO, G. (Ed.) Writing material culture. London: Bloomsbury Academic, 2015. p.72-91.

VEYNE, P. L'inventaire des différences. Histoire et Sociologie. Paris: Seuil, 1977.

Ulpiano T. Bezerra de Meneses é professor emérito da Faculdade de Filosofia, Letras e Ciências Humanas da Universidade de São Paulo. @ - utbm@uol.com.br

Recebido em 13.3.2015 e aceito em 16.3.2015.

${ }^{\text {I }}$ Faculdade de Filosofia, Letras e Ciências Humanas da Universidade de São Paulo, São Paulo-SP, Brasil. 
